\title{
ESCOLA E EDUCAÇÃO EM VALORES: REFLETINDO PARA ALÉM DOS MUROS ESCOLARES
}

\author{
Claudiele Carla Marques da Silva \\ Universidade Estadual Paulista Júlio de Mesquita Filho - UNESP. Presidente Prudente - SP. E-mail: \\ claudielecarla@hotmail.com Fomento: FAPESP
}

\section{RESUMO}

Nesse trabalho apresentamos resultados da pesquisa "Educação Moral, escola e comunidade: uma relação (des)articulada?" em que discutimos as relações entre projetos de Educação em Valores desenvolvidos em escolas e a comunidade de seu entorno. Investigamos essas relações na literatura específica e em 169 experiências coletadas por meio de questionários em escolas públicas do Ensino Fundamental II e Médio do estado de São Paulo. As relações são assinaladas na literatura como complexas, não lineares e marcadas por tensões e contradições. Nas análises das experiências de educação Moral desenvolvidas pelas escolas $54 \%$ afirmaram estabelecer relações com seu entorno, sendo que duas tendências de respostas mais se destacaram: primeiro, as relações são estabelecidas devido aos problemas, carências ou valores vivenciados pelos alunos e suas famílias na comunidade; segundo, por conta das especificidades e necessidades do bairro e seus membros, bem como, pela necessidade de participação dos pais e professores nos projetos.

Palavras-chave: Educação Moral. Educação em Valores. Escola. Comunidade. Projetos.

\section{SCHOOL AND COMMUNITY: REFLECTING PARTNERSHIPS FOR VALUES EDUCATION}

\begin{abstract}
We present survey results "Moral Education, school and community: one (dis) articulated relationship" in which we discuss the relationship between Values Education projects developed in schools and the community around it. We investigated these relationships in the literature and 169 experiences collected through questionnaires in public schools in the elementary and high school in the state of São Paulo. Relationships are highlighted in the literature as complex, nonlinear and marked by tensions and contradictions. In the analysis of the experiences of Moral education developed by schools $54 \%$ said establishing relationships with its surroundings, with two trends responses stood out: first, relations are established due to the problems, needs or values experienced by students and their families in the community; second, due to the specificities and needs of the neighborhood and its members, as well as the need to involve parents and teachers in the projects.
\end{abstract}

Keywords: Moral Education. Community.Public school. 


\section{INTRODUÇÃO}

Vivemos em uma situação de crise relacional dentro da escola, causada pela violência que ocorre dentro e fora dela. São cada vez mais frequentes as queixas dos profissionais da educação sobre desrespeito, indisciplina e intolerância dos alunos bem como sobre a suposta ausência das famílias na educação de seus filhos (SHIMIZU et al., 2010). Esse cenário é acompanhado pelo sentimento de crise de valores da sociedade atual (JARES, 2005; LA TAILLE, 2009; LA TAILLE; MENIN, 2009).

Nesse contexto, políticas públicas estão sendo elaboradas a fim de servir de base para que se possa concretizar uma educação pautada em valores éticos e de direitos humanos, baseadas ora na convivência harmônica e democrática, ora nas discussões de certos documentos, como a Declaração Universal dos Direitos Humano que enfatizam a finalidade da escola como formação integral do aluno e não apenas de conhecimentos científicos e tecnológicos. (BRASIL, 1998, 1997)

Essa formação integral envolve, além de outros aspectos, a educação em valores e ética, a sensibilidade estética e aprendizagem de resolução de conflitos de forma pacífica e dialogada. Essa educação deve estar interligada com aspectos da realidade do aluno, com seus interesses e de sua comunidade.

Diversos autores (CORTINA, 2003; DELVAL, 2006; SERRANO, 2002) destacam a importância das relações entre escola e comunidade como necessárias para uma Educação Moral contextualizada e significativa para os alunos, que podem conduzi-los a reflexões e ações sobre os problemas do entorno.

Essa pesquisa teve como objetivo verificar e analisar se há relações da comunidade com a escola em experiências de Educação Moral e/ou em Valores e como elas acontecem.

\section{DESENVOLVENDO A PESQUISA: OS CAMINHOS TRAÇADOS}

Por ser um tema que apresenta características variáveis e inexatas, optamos por uma abordagem de pesquisa predominantemente qualitativa, tendo em vista a complexidade do fenômeno estudado.

Essa pesquisa teve como objetivo verificar e analisar se há relações da comunidade com a escola em experiências de Educação Moral e/ou em Valores e como elas acontecem. Para tanto, investigamos essas relações na literatura específica da área e também em 169 experiências desenvolvidas em escolas públicas do estado de São Paulo. O projeto foi submetido ao Comitê de Ética em Pesquisa da Universidade Estadual Paulista "Júlio de Mesquita Filho" que teve seu parecer aprovado sob processo n으 74/2011. 
Essas experiências de Educação Moral e/ou em Valores foram coletadas por meio de questionários online ou impressos aplicados junto a diretores, coordenadores pedagógicos e/ou professores de escolas públicas de ensino fundamental II ( $6^{\circ}$ ao $9^{\circ}$ ano) e médio do estado de São Paulo em uma pesquisa anterior nomeada "Projetos bem sucedidos de Educação Moral: em busca de experiências brasileiras" (MENIN, 2010), desenvolvida no ano de 2009 e 2010.

Os questionários foram analisados por meio do programa Alceste (AnalyseLexicale par Contexte d'un Ensemble de Segments de Texte) e, como complemento, foi utilizado a técnica de análise de conteúdo, segundo Bardin (2004).

\section{RESULTADOS}

A seguir, apresentamos os resultados advindos do desenvolvimento da pesquisa. No primeiro subcapítulo discutimos como as relações entre escola, educação moral e a comunidade são tecidas na literatura especifica da área. No segundo subcapítulo, apresentamosas relações estabelecidas entre escola e comunidade nos projetos desenvolvidos de Educação Moral.

\section{AS RELAÇÕES ENTRE ESCOLA, COMUNIDADE E EDUCAÇÃO MORAL: O QUE NOS PROPÕE A LITERATURA}

Vários estudos (CASTRO; REGATTIERI, 2009) têm mostrado que as relações entre a escola e seu entorno são precárias, isto porque a comunidade não consegue se apropriar da escola, isto é, se sentir reconhecido e pertencente a ela.

O fato de as relações entre escola e comunidade serem precárias pode ser explicado pela errônea concepção, ainda muito presente, de que a escola é um lugar independente do seu contexto, que deve apenas transmitir conhecimentos, em que o aluno é tido como um ser passivo que deve limitar-se a reproduzir esses conhecimentos.

Além disso,Thin (2006) afirma que outra dificuldade encontrada para criar relações entre escola e comunidade refere-se às concepções dos pais dos alunos e dos membros da comunidade sobre a função da escola e dos conhecimentos ali adquiridos. O autor destaca uma tensão existente entre os pais dos alunos e a escola no que tange os conhecimentos pedagógicos.

[...] observamos uma oposição ou tensão entre pais, que esperam da escola conhecimentos que sejam apreensíveis em sua operacionalidade imediata e prática, e a lógica pedagógica, que se inscreve na duração, que coloca os sentidos da aprendizagem em objetivos mais distantes e mais gerais, ou mais universais, cujos fins só se desvelam em longo prazo, no domínio dos procedimentos intelectuais abstratos. (THIN, 2006, p. 221). 
Podemos mencionar que a Educação Moral ou a educação em valores, além de exceder os "conteúdos escolares tradicionais", se insere nos objetivos mais gerais e de longo prazo da instituição, o que pode dificultar a aceitação dos pais e da comunidade, já que muitas vezes esses sujeitos priorizam os conhecimentos que têm utilidade prática e imediata.

Nogueira (1991) e Thin (2006) têm demonstrado, em seus estudos, as dificuldades dessas relações entre escola e comunidade, quando se trata das classes mais populares da sociedade. Conforme Nogueira (1991) há unanimidade entre pesquisadores ao afirmarem que a relação entre as classes populares e a escola é uma relação fortemente marcada pelo seu caráter contraditório e por uma tensão inerente.

Os resultados a que têm chegado às pesquisas sobre o tema - quer no âmbito dos discursos, quer no âmbito das práticas dos atores sociais - tendem a mostrar que essa categoria social experimenta uma verdadeira ambiguidade face à instituição escolar. Ao mesmo tempo em que expressa sentimentos e atitudes de rejeição e de distanciamento em relação a ela, como que reconhecendo e reagindo ao processo de identificação negativa a que ela fica exposta [...], não abdica de seu direito à instituição, aceitando-a. (NOGUEIRA, 1991, p. 34).

Complementando a afirmação acima, Thin (2006) parte do princípio que famílias e escolas têm lógicas de socialização diferentes. Essas diferenças encontram-se, por exemplo, na autoridade, na linguagem, nos jogos e, muitas vezes, na diferença de classe social entre os professores e os membros da comunidade do entorno da escola. Além disso, Thin (2006) assinala que as relações entre escola e famílias populares se fundam sobre uma "confrontação desigual entre dois modos de socialização: um, escolar e dominante, outro, popular e dominado" (THIN, 2006, p. 212). Essas diferenças inerentes entre agentes escolares e comunidade geram um distanciamento e, muitas vezes, uma concepção negativa de ambas as partes.

Portanto, a relação entre escola e comunidade é complexa, não linear e marcada por tensões e contradições. Isto porque essa relação se fundamenta por diferentes sujeitos, ou seja, professores, membros da comunidade, alunos e famílias que têm maneiras diversas de comunicação, concepções sobre a importância da escola no bairro e sobre a necessidade ou não de participar das atividades desenvolvidas pela escola.

Quando se trata da Educação Moral, as relações da escola com a comunidade são especialmente importantes, pois a formação do sujeito moral é uma ação complexa que se desenvolve em inúmeras circunstâncias e espaços escolares e não escolares. Autores (CORTINA, 2003;GOERGEN, 2005) vêm defendendo essa ideia ao afirmar que não podemos desconsiderar a comunidade quando pensamos em formas de educar moralmente e/ou em valores na escola. 
Delval (2006)indica que a escola pode ancorar as relações com a comunidade em várias direções: as escolas devem se transformar em centros de cultura para a comunidade do entorno, ou seja, abertas a todos; as atividades escolares deveriam receber contribuições culturais de todos os membros da comunidade; a escola deveria ser um laboratório em que os alunos aprendessem a analisar os problemas sociais e culturais da comunidade do entorno e da sociedade; a escola poderia oferecer soluções para os problemas que ocorrem na comunidade do entorno.

Para finalizar a discussão sobre essas possíveis relações, entre escola e comunidade, indicadas pela literatura, concordamos com Ribeiro et al. (2005) ao afirmarem que:

[...] para alcançar uma educação de qualidade para todos no Brasil [e aí está inclusa a Educação Moral], se torna estratégica a aliança entre os profissionais de ensino e a população, assim como das organizações da sociedade civil com os órgãos públicos das diversas esferas de governo e com as agências internacionais. A partir do enfrentamento das divergências, dos conflitos de interesse e das relações desiguais de poder, a partir do estabelecimento de alianças, da partilha de informações e da integração dos diferentes, vão-se construindo democraticamente novos sentidos sobre a qualidade da educação na escola. (RIBEIRO et al., 2005).

\section{VOLTANDO O OLHAR SOBRE A AÇÃO: AS RELAÇÕES ESTABELECIDAS ENTRE ESCOLA E COMUNIDADE NOS PROJETOS DE EDUCAÇÃO MORAL}

Analisamos os projetos de Educação Moral desenvolvidos nas escolas do estado de São Paulo para verificar quais relações são estabelecidas com a comunidade de seu entorno. Para tanto, investigamos no questionário a questão principal que trata dessas possíveis relações "De alguma forma, a comunidade em torno da escola provocou essa experiência, se sim, como?".

Das 169 experiências analisadas, 92 afirmaram que, de alguma forma, a comunidade em torno da escola provocou essa experiência, isto é, $54,4 \%$ das respostas foram afirmativas. Essas respostas abertas foram tratadas por meio do programa Alceste, que as selecionou e as dividiu em cinco classes diferentes.

Realizamos a leitura de cada classe a partir de suas palavras mais significativas, por meio dos exemplos de respostas típicos de cada classe e por meio da leitura de cada experiência. Em função dessa análise, gerou-se a denominação dessas classes que apresentamos no Quadro 1. 
Quadro 1. Denominação das classes em relação à questão “De alguma forma a comunidade em volta da escola provocou essa experiência?"

\begin{tabular}{ll}
\hline Classe & Denominação \\
\hline Classe 1 & $\begin{array}{l}\text { Relações estabelecidas devido a problemas ou falta de tempo das } \\
\text { famílias }\end{array}$ \\
Classe 2 & $\begin{array}{l}\text { Relações constituídas por conta dos valores e experiências vivenciados } \\
\text { pelos alunos e famílias }\end{array}$ \\
Classe 3 & $\begin{array}{l}\text { Relações devidas às carências dos alunos, vivenciadas no entorno } \\
\text { escolar }\end{array}$ \\
Classe 4 & Relações instituídas pelas necessidades apresentadas pela comunidade \\
Classe 5 & Relações estabelecidas devido ao papel dos pais e dos professores na \\
& Educação Moral
\end{tabular}

Fonte: dados do autor

\section{DISCUSSÃO}

Analisando os dados das cinco classes de respostas, vemos que duas tendências mais se destacaram: primeiro, as relações são estabelecidas devido aos problemas, carências ou valores vivenciados pelos alunos e suas famílias (Classe 1 e 2); segundo, por conta das especificidades e necessidades do bairro, bem como pela necessidade de participação dos pais e professores nos projetos (Classe 3, 5 e 4).

As relações estabelecidas por conta dos valores e experiências vivenciados pelos alunos (classe 2) e devido aos problemas, falta de condições das famílias ou de tempo por conta do trabalho (classe 1 ) totalizam $32,5 \%$ das respostas. Pela leitura das experiências, podemos afirmar quea escola estabelece relações com a comunidade, que, nesse caso, se restringe à família dos alunos, por considerar que os valores transmitidos por ela estão corrompidos. A seguir, falas típicas dessa classe de resposta:

"Devido ao fato de pais muito ausentes na vida do filho, com grande número de consanguíneos, alcoolismo e segunda união há alunos que se envergonham por isso; daí buscar aproximação envolvendo-os na participação de projetos na escola". (Diretor atuando em escola de ensino fundamental).

"Considerando que os familiares cumprem longas jornadas de trabalho, não dispõem de tempo para o diálogo em família." (Diretor atuando em escola de ensino fundamental e médio).

Nessa classe, podemos compreender que a escola se relaciona com a comunidade em consequência de problemas apresentados pelas famílias dos alunos, como drogas, alcoolismo, violência, entre outros, e também em decorrência do pouco tempo de convivência entre famílias e alunos por conta da longa jornada de trabalho dos pais. 
A segunda tendência de respostas assinala relações estabelecidas devido às necessidades e especificidades apresentadas pela comunidade (Classe 4), às carências vivenciadas pelos alunos na comunidade (Classe 3)e destacam o papel dos pais e dos professores na Educação Moral (Classe 5). A seguir, apresentamos respostas dessa segunda tendência:

"Antes de iniciar qualquer projeto é preciso diagnosticar as necessidades da comunidade e assim descobrir a importância de elaborar tais projetos"(Coordenador pedagógico atuando em escola de ensino fundamental).

Esse tipo de relação entre escola e comunidade vai ao encontro do que tem sido proposto nos PCN (BRASIL, 1998), em que há a indicação de que é necessário que a escola realize uma investigação sobre a realidade do aluno, com o intuito de conhecer as características das famílias, da estrutura que a comunidade tem para atender seus alunos e familiares, como postos de saúde, lazer, cultura, etc.

\section{CONSIDERAÇÕES FINAIS}

É essencial a compreensão de que o desenvolvimento moral constitui um longo processo que se desenvolve durante toda a vida, necessitando de intervenções contínuas da escola para que o sujeito possa alcançar sua progressiva autonomia moral. Deste modo, acreditamos que o desenvolvimento moral é decorrente de um processo contínuo que se dá por meio das relações estabelecidas entre indivíduos em diferentes espaços.

Assim, quando refletimos sobre a formação moral do indivíduo, que se dá na interação do com seu meio social, é imprescindível pensar no papel da comunidade em torno da escola. É importante destacar que esse ambiente, a comunidade, tem um importante papel na formação moral do sujeito, pois as crianças e jovens ainda passam parte de seu tempo nesse espaço e as relações ali estabelecidas influirão sobre o seu desenvolvimento.

\section{REFERÊNCIAS}

BARDIN, L. Análise de Conteúdo. 3. ed. Lisboa, Portugal: Edições Setenta, 2004.

BRASIL. Secretaria de Educação Fundamental; Parâmetros Curriculares Nacionais; terceiro e quarto ciclo: apresentação dos temas transversais - Brasília: Ministério da Educação, Secretaria da Educação Básica, 1998.

BRASIL. Secretaria de Educação Básica, Fundo Nacional de Desenvolvimento da Educação. Ética e cidadania: construindo valores na escola e na sociedade. Brasília: Ministério da Educação, Secretaria da Educação Básica, 2007. 
CASTRO, M., REGATTIERI, M. (Orgs). Interação escola-familia: subsídios para práticas escolares. Brasília: UNESCO, Ministério da Educação, 2009.

CORTINA, A. O fazer ético: guia para Educação Moral. São Paulo: Moderna, 2003.

DELVAL, J. Manifesto por uma escola cidadã. Campinas: Papirus, 2006.

GOERGEN, P. (Orgs.) Ética e Educação: reflexes filosóficas e históricas. Campinas: HISTEDBR, 2005.

JARES, C. X. R. Educar para a verdade e para a esperança. Em tempos de globalização, guerra preventiva e terrorismos. Porto Alegre: Artmed, 2005.

LA TAILLE, Y. Formação ética: do tédio ao respeito de si. Porto Alegre: Artmed, 2009.

LA TAILLE, Y; MENIN, M. S. (Orgs.) Crise de Valores ou Valores em crise? Porto Alegre: Artmed, 2009.

MENIN, M. S. S. Projetos bem sucedidos de Educação Moral: em busca de experiências brasileiras. In: Congresso de Pesquisas em Psicologia e Educação Moral: crise de valores ou valores em crise?, 1., 2009, Campinas. Anais... Campinas: UNICAMP/FE, 2010.

NOGUEIRA, M. A. Trajetórias escolares, Estratégias Culturais e Classes Sociais. Teoria \& Educação. Porto Alegre, n.3, p. 89-112, 1991.

RIBEIRO, V. M.; RIBEIRO, V. M; GUSMÃO, J. B. Indicadores de qualidade para a mobilização da escola. Cadernos de Pesquisa, São Paulo,v. 35, n. 124, p. 227-251, jan./abr. 2005.

http://dx.doi.org/10.1590/S0100-15742005000100011

SERRANO, G. P. Educação em valores: como educar para a democracia. Porto Alegre: Artmed, 2002.

SHIMIZU A. M. et al. Representações de educadores de escolas brasileiras a respeito de educação em valores morais. In: Reunião Anual da ANPED, 33., 2010, Caxambu. Anais... ANPED. 2010.

THIN, D. Para uma análise das relações entre famílias populares e escola: confrontação entre lógicas socializadoras. Revista Brasileira de Educação, Rio de Janeiro, v. 11, n. 32, maio/ago., 2006. 